Journal of Animal and Veterinary Advances $10(4)$ : 484-488, 2011

ISSN: $1680-5593$

(C) Medwell Journals, 2011

\title{
Probiotic Activities of Lab in Endometritis: Probiotic Activities of Three Lactic Acid Bacteria Strains Isolated from Healthy Bovine Cervix: In Vitro Adherence to Immortalized Endometrial Epithelial Cells and Antimicrobial Properties
}

\author{
${ }^{1,2}$ Xuefeng Qi, ${ }^{2}$ Dongning Bai, ${ }^{2}$ Xianjun Zhao, ${ }^{2}$ Aihua Wang, ${ }^{2} \mathrm{Yi}$ Li and ${ }^{1,2}$ Yaping Jin \\ ${ }^{1}$ Key Laboratory of Animal Reproductive Endocrinology and Engineering, \\ Agriculture Ministry of P.R. China, 712100 Yangling, P.R. China \\ ${ }^{2}$ College of Veterinary Medicine of Northwest A and F University, \\ 712100 Yangling, P.R. China
}

\begin{abstract}
The ability of three Lactic Acid Bacteria (LAB), i.e., Lactobacillus acidophilus, Enterococcus faecalis and Enterococcus cecorum that isolated from cervical mucus in health cattle to adhere to immortalized Endometrial Epithelial Cells (EEC) and to affect the adhesion of two main endometritis-associated pathogens, Escherichia coli and Staphylococcus aureus were investigated. All probiotic strains exhibited strong adhesion levels to the cell lines and the adhesion levels of L. acidophilus was significantly higher as compared to that of E. faecalis or E.cecorum ( $\mathrm{p}<0.05$ ). In coculture assays, a significant decrease in the number of adhering pathogens was observed, using either preincubation, postincubation or coincubation of the pathogens with these LAB. L.acidophilus exhibited strong antagonistic activity against $E$. coli ( $<<0.01$ ), nevertheless, E. Faecalis and E. cecorum showed strong inhibitory effect on S. aureus ( $<0.01$ ). In conclusion, the ability of LAB tested to inhibit the adhesion of endometritis-associated pathogens is highly specific and depends on both the probiotic and pathogen strains.
\end{abstract}

Key words: Immortalized endometrial epithelial cell, lactic acid bacteria, adherence, antimicrobial property, endometritis-associated pathogen, China

\section{INTRODUCTION}

Uterine infections are one of the most important disorders in postpartum cows (Azawi, 2008). These infections cause high economic losses due to prolonged days open and prolonged intercalving intervals, resulting in involuntary culling (Földi et al., 2006; Azawi et al., 2007).

In the postpartum cow, the pathogenic bacteria that are frequently isolated from cases of endometritis are Escherichia coli, Staphylococcus sp. and Streptococcus sp. (Zerbe et al., 2001; Petit et al., 2009). The conventional treatments for uterine infection recommended the use of antibiotics as systemic route of administration in cows with toxic puerperal metritis (Amirid et al., 2003; Sheldon et al., 2004) but these treatments are associated with the increasing frequency of drug-resistant pathogenic bacteria and residues in animal products. Alternative therapeutic agents need to be sought and it has been suggested that the administration of Lactic Acid Bacteria (LAB) can restore ecological balance in the vagina by controlling the infectivity of pathogenic microbes (Abad and Safdar, 2009). Possible mechanisms of the health benefits provided by probiotics include immune exclusion, competition for adhesion sites and production of antimicrobial agents such as bacteriocins (Foligne et al., 2010; Guo et al., 2010). Antagonistic effect against pathogens and temporary colonization of the gastrointestinal and urogenital tract have been demonstrated for some probiotics (Kon et al., 2008; Johnson et al., 2009; Ruiz et al., 2009). However, the effect of probiotics during postpartum uterine infection in vitro has not been thoroughly investigated for the limited information of highly suitable endometrial epithelial cell vitro model. Previous studies have indicated that mucus adhesion properties are more dependent on the probiotics strain than on the host (Tuomola et al., 1999; Rinkinen et al., 2003). In this study, immortalized hircine Endometrial Epithelial Cells (EEC) was used as vitro model and the adherence of various strains of $\mathrm{LAB}$ as well as pathogenic bacteria to $\mathrm{EEC}$ was compared. The abilities of these LAB strains to inhibit the adhesion of endometritisassociated bacterial pathogens were also examined.

\section{MATERIALS AND METHODS}

Bacterial strains and culture conditions: Three lactic acid bacteria, including Lactobacillus acidophilus YL305,

Corresponding Author: Yaping Jin, College of Veterinary Medicine of Northwest A and F University, 712100, Yangling, China 
Enterococcus faecalis YL303, Enterococcus cecorum YL306 were originally derived from cervical mucus in cattles that had no history of metritis infection. The LAB strains were cultured in De Man, Rogosa, Sharpe (MRS) broth at $37^{\circ} \mathrm{C}$ under anaerobic conditions. Bacterial pathogens used were Escherichia coli C83917 and Staphylococcus aureus C56008 which were purchased from the China Veterinary Culture Collection Center (Beijing, China). They were clinical isolated from cervical mucus in postpartum metritis cattle and were grown in Luria-Bertani (LB) medium at $37^{\circ} \mathrm{C}$ under aerobic condition. All strains were stored in $-80^{\circ} \mathrm{C}$ with $20 \%$ sterile glycerol until needed.

Cell lines and culture conditions: The endometrial epithelial cell lines from g oat were kindly provided by Dr Y.P. Jin (Northwest A and F University, Yangling, China) immortalized by transfected the human Telomerase Reverse Transcriptase (hTERT) into EECs (Wu et al., 2010).

The morphological and immunocytochemical characteristics of the immortalized lines closely resembled those of their tissues of origin and primary cultures. The cells were cultured and maintained in Dulbecco's Modified Eagle Medium (DMEM)-Hank F12 (GIBCO, Invitrogen Corporation, Grand Island, NY) supplemented with 5\% fetal calf serum (FCS; Atlanta Biologicals, Lawrenceville, GA), antibiotics (100 $\mathrm{U} \mathrm{mL}^{-1}$ penicillin, $100 \mu \mathrm{g} \mathrm{mL}$ streptomycin; Gibco) at $37^{\circ} \mathrm{C}$ in a $5 \% \mathrm{CO}_{2}-95 \%$ air atmosphere.

In vitro adhesion assays on EEC: Adhesion of the bacterial was assayed by seeding cell lines in 24-well tissue culture plates at $2.5 \times 10^{5}$ epithelial cells/well and allowing them to grow to complete confluence. Prior adhesion assays EEC monolayers were washed twice with DMEM without antibiotics (streptomycin and penicillin). Bacterial strains were cultivated in MRS broth under micro-aerophilic conditions at $37^{\circ} \mathrm{C}$. Cells were harvested at the stationary phase after $18 \mathrm{~h}$ of incubation at an amount corresponding to approximately $10^{8}$ colony forming units (CFU) $\mathrm{mL}^{-1}$ and washed three times in buffered saline PBS ( $\mathrm{pH}$ 7.2). The volume of the culture with the required number of CFU was determined by plating serial dilutions of bacterial suspensions on MRS agar plates and incubating the plates in micro-aerophilic conditions at $37^{\circ} \mathrm{C}$ overnight. In the following procedure DMEM without antibiotics was used. Bacterial cells were re-suspended in DMEM and added onto the EEC monolayer at the concentration of approximately $10^{8} \mathrm{CFU}$ well ${ }^{-1}$. After $1 \mathrm{~h}$ of incubation carried out at $37^{\circ} \mathrm{C}$ under $5 \% \mathrm{CO}_{2}$ air atmosphere, suspensions were removed and the monolayers were washed three times with DMEM to release unbound bacteria. For qualitative analysis, the cell monolayers and the bacteria were methanol fixed and stained with Gram stain (Bonetti et al., 2003). For each monolayer on a glass coverslip, the numbers of adherent bacteria to the EEC were counted in 20 random microscopic areas according to the method of Gopal et al. (2001). Assays were carried out in triplicate.

Inhibition of pathogens adhesion to EEC: Three different procedures were used in order to differentiate exclusion, competition or displacement of the endometritisassociated bacterial pathogens by LAB strains used in this study. For exclusion tests, hircine EEC monolayers were cultured and washed as previously described and incubated with lactobacilli $\left(10^{8} \mathrm{CFU}\right.$ well $\left.{ }^{-1}\right)$ for $30 \mathrm{~min}$. Afterward, nonadhering lactobacilli were removed, Escherichia coli C83917 or Staphylococcus aureus C56008 $\left(10^{8} \mathrm{CFU}_{\text {well }}{ }^{-1}\right)$ was added and incubation was continued for a further $30 \mathrm{~min}$. For competition tests, lactobacilli and any of the pathogens and the endometrial cells were mixed and incubated for $1 \mathrm{~h}$. For displacement tests, the pathogens and the endometrial epithelial cells were incubated together for $30 \mathrm{~min}$ after removal of nonadhering pathogens lactobacilli were added and incubation was continued for a further $30 \mathrm{~min}$. Unbound bacteria were then washed and bound bacteria were released and lysated. Adherence of the pathogens was performed in the presence of $0.5 \%$ methyl mannose to avoid type-1-mediated adherence, a nonspecific interaction. The number of viable bacteria adhering to the EEC was determined by plating serial dilutions on MRS plates (for Lactobacillus) or LB plates (for Escherichia coli or Staphylococcus aureus). The inhibition of pathogens adhesion was quantified by comparison of CFU counts of adhered bacteria to the counts in the control experiments without lactobacilli. Inhibition was conducted in three independent experiments and each assay was performed in triplicate.

Statistical analysis: Data was analyzed by Kruskal-Wallis one way Analysis of Variance (ANOVA) using commercially available software (SPSS 16.0, Chicago, IL, USA). Results were logarithmically transformed to obtain geometric means. Comparisons of means were conducted using student's t-test or a Mann-Whitney rank sum test. Results of all statistical analyses were considered significant only if $\mathrm{p}<0.05$.

\section{RESULTS AND DISCUSSION}

In the present study, immortalized endometrial epithelial cell monolayer grown on the glass was used as an in vitro model for investigation of three LAB (one 
Lactobacillus and two Lactococcus) adhesive to the uterine epithelium. Besides lake of mucus production, this model offers a number of interesting features ideal for investigation bacterial adherence. Strong adhesion levels of all lactobacilli strains examined were exhibited in this study and these bacteris adhered to endometrial epithelial cells in the range of $38.5-70$ bacteria $1 \mathrm{cell}^{-1}$. As shown in Fig. 1, the adhesion levels of $L$. acidophilus was significantly higher as compared to that of E. faecalis or E. cecorum $(\mathrm{p}<0.05)$.

This could also be related to the fact that different structures of bacteria are implicated in the interactions between bacteria strains and endometrial epithelial cells (Avall-Jaaskelainen and Palva, 2005; Mobili et al., 2009). Microscopical observation of gram-stained preparation showed bacterial clusters of L. acidophilus or E. faecalis randomly dispersed on the cell surface (Fig. 2a, b). $E$. cecorum appeared to adhere individually or in pairs (Fig. 2c). Adherence of bacteria to the epithelial cells is an important prerequisite for colonization by microorganisms

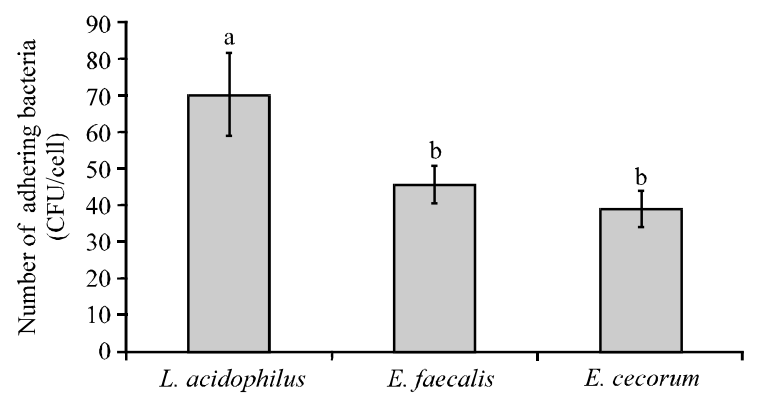

Fig. 1: Each adhesion assays was conducted in triplicate with cells from three successive passages. Adhesion assays were monitored after $1 \mathrm{~h}$ of incubation. The figure presents mean numbers \pm standard deviation of bacteria adhering per epithelial cell. Valus with different superscripts letters are significantly different $(\mathrm{p}<0.05)$ and virulence manifestations (Kon et al., 2008; Johnson et al., 2009). Inhibiting the adhesion of pathogenic bacteria to their receptor could decrease the uterine colonization and in consequence modify the process of pathogenicity (Voravuthikunchai et al., 2006). In this study, three lactobacilli strains tested interfered with the adhesion process to endometrial epithelial cells of two pathogens E. coli and S. aureus.

The adherence of the two pathogens was significantly decreased by addition of probiotics strains ( $p<0.05$ or $p<0.01$ ), regardless of whatever the probiotics strains was added before, during or after the incubation with the pathogen (Fig. 3). The presence of these probiotics may impede the access of pathogens to tissue receptors by steric hinderance and that may explain the decrease of adhesion of the pathogens in the presence of probiotics tested (Jankowska et al., 2008). It is important to note that although, the level of adhesion of $L$. acidophilus to endometrial epithelial cells was significantly higher than those of E. Faecalis and $E$. cecorum there was no significant difference of the adherence inhibition of two pathogenic bacteria to epithelial cells among three LAB examined. The machanism ( $\mathrm{s}$ ) underlying this phenomenon may involve not only competition for eukaryotic cell receptors but also an action of production or secreted by lactobacilli antimicrobial compound (Abad and Safdar, 2009). Several studies have shown that the ability of selected strains of Lactobacillus to inhibit the adhesion of pathogenic bacteria is highly specific and depends on both the probiotic and pathogen strains (Jankowska et al., 2008; Lee et al., 2009; Zhang et al., 2010).

In the experimental system, L. acidophilus exhibited strong antagonistic activity against $E$. coli (p<0.01), nevertheless, E. Faecalis and E. cecorum showed strong inhibitory effect on $S$. aureus $(\mathrm{p}<0.01)$. This indicates the need of a case-by-case characterization of the probiotic

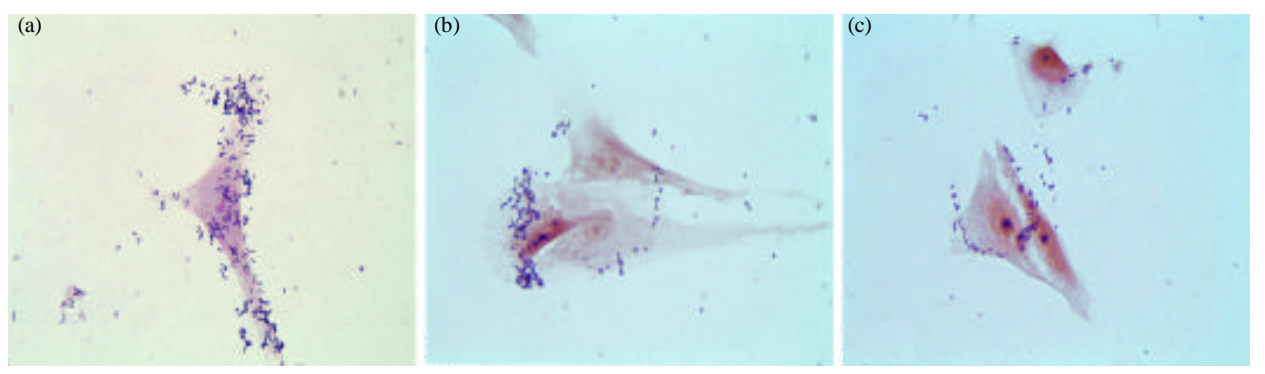

Fig. 2: Adhesion of bacteria strains to endometrial epithelial cell cultures observed using light microscopy after Gram-staining; (a) L. acidophilus YL305; (b) E. faecalis YL303 and (c) E. cecorum YL306 


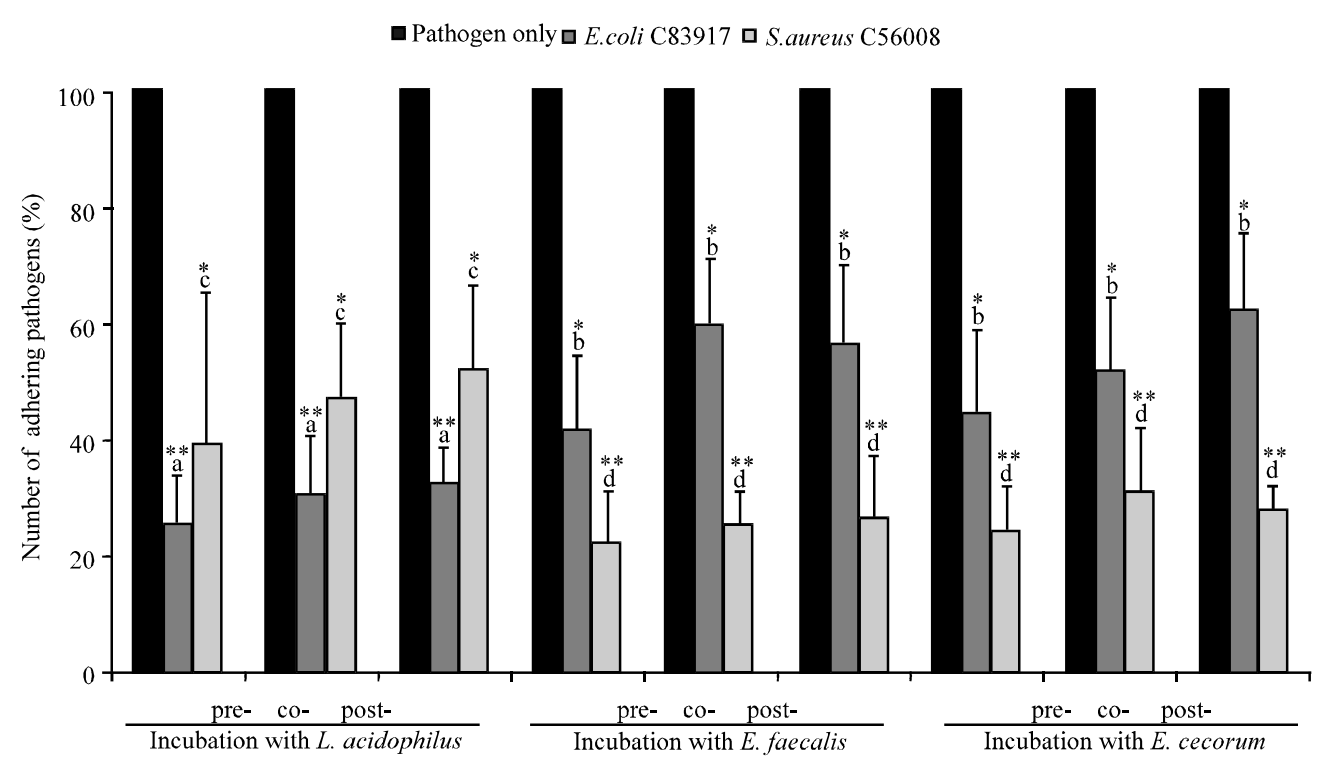

Fig. 3: Competitive inhibition of adhesion to endometrial epithelial cells of two pathogens, Escherichia coli C83917 and Staphylococcus aureus C56008 in preincubation, coincubation and postincubation assays with Lactobacillus acidophilus, Enterococcus faecalis and Enterococcus cecorum. Results are expressed as percentage (means \pm standard deviations) of adherence compared to the control (pathogen only, 100\%). Asterisks denote adhesion values significantly different from the controls within the same $\mathrm{LAB},{ }^{*} \mathrm{p}<0.05,{ }^{* *} \mathrm{p}<0.01$. Valus with different superscripts letters are significantly different $(p<0.05)$ from pathogen incubated with other LAB within the same protocol

strains. It has to be taken under consideration the relationship between the inhibitory effect of LAB and the presence of specific adhesion molecules and receptors for which probiotic and pathogen are competing.

\section{CONCLUSION}

In this study, the lactic acid bacteria strains used in this study may protect the uterine epithelium through a serious of barriers and interference mechanisms. The extent to which these in vitro results correspond to in vitro conditions remains to be determined; clinical trials are needed to assess the benefits of probiotic organism consumption in the management of postpartum uterine infection.

\section{ACKNOWLEDGEMENTS}

This research was financially supported by Foundation for The Excellent Youth Scholars and Key Teacher of Northwest A and F University (Grant no. Z111020902), National Natural Science Foundation of China (Grant No. 30901 089), Doctoral Fund of Education Ministry of China (Grant no. 20090204120011).

\section{REFERENCES}

Abad, C.L. and N. Safdar, 2009. The role of Lactobacillus probiotics in the treatment or prevention of urogenital infections-a systematic review. J. Chemother., 21: 243-252.

Amirid, G.S., G.C. Fthenakis, J. Dafopoulas, T. Papanikolaou and V.S. Mavrogianni, 2003. Use of cefquinome or prevention and treatment of bovine endometritis. J. Vet. Pharmacol. Therapeutics, 26: 387-390.

Avall-Jaaskelainen, S. and A. Palva, 2005. Lactobacillus surface layers and their applications. FEMS Microbiol. Rev., 29: 511-529.

Azawi, O.I., 2008. Postpartum uterine infection in cattle. Anim. Reprod. Sci., 105: 187-208.

Azawi, O.I., S.N. Omran and J.J. Hadad, 2007. Clinical, bacteriological and histopathological study of toxic puerperal metritis in Iraqi buffalo. J. Dairy Sci., 90: 4654-4660.

Bonetti, A., L. Morelli, E. Campominosi, E. Ganora and F. Sforza, 2003. Adherence of Lactobacillus plantarum P17630 in soft-gel capsule formulation versus doderleins bacillus in tablet formulation to vaginal epithelial cells. Minerva. Ginecol., 55: 279-287. 
Foligne, B., J. Dewulf, J. Breton, O. Claisse, A. LonvaudFunel and B. Pot, 2010. Probiotic properties of nonconventional lactic acid bacteria: Immunomodulation by Oenococcus oeni. Int. J. Food. Microbiol., 140: 136-145.

Földi, J., M. Kulcsar, A. Pecsi, B. Huyghe and C. de Sa et al., 2006. Bacterial complications of postpartum uterine involution in cattle. Anim. Reprod. Sci., 96: 265-281.

Gopal, P.K., J. Prasad, J. Smart and H.S. Gill, 2001. In vitro adherence properties of Lactobacillus rhamnosus DR20 and Bifidobacterium lactis DR10 strains and their antagonistic activity against an enterotoxigenic Escherichia coli. Int. Food Microbiol., 67: 207-216.

Guo, X.H., J.M. Kim, H.M. Nam, S.Y. Park and J.M. Kim, 2010. Screening lactic acid bacteria from swine origins for multistrain probiotics based on in vitro functional properties. Anaerobe, 16: 321-326.

Jankowska, A., D. Laubitz, H. Antushevich, R. Zabielski and E. Grzesiuk, 2008. Competition of Lactobacillus paracasei with Salmonella enterica for adhesion to Caco-2 cells. J. Biomed. Biotechnol., 2008: 1-6.

Johnson, A.M., R.S. Kaushik, D.H. Francis, J.M. Fleckenstein and P.R. Hardwidge, 2009. Heat-labile enterotoxin promotes Escherichia coli adherence to intestinal epithelial cells. J. Bacteriol., 191: 178-186.

Kon, S.Y., S. George, V. br Zel, R. Moxley, D. Francis and R.S. Kaushik, 2008. Porcine intestinal epithelialcell lines as a new in vitro model for studying adherence and pathogenesis of enterotoxigenic Escherichia coli. Vet. Microbiol., 130: 191-197.

Lee, D.Y., Y.S. Seo, N. Rayamajhi, M.L. Kang, S.I. Lee and H.S. Yoo, 2009. Isolation, characterization and evaluation of wild isolates of Lactobacillus reuteri from pig feces. J. Microbiol., 47: 663-672.

Mobili, P., A. Londero, T.M.R. Maria, M.E.S. Eusebio, G.L. de Antoni, R. Faustob and A. Gomez-Zavaglia, 2009. Fausto characterization of S-layer proteins of Lactobacillus by FTIR spectroscopy and defferential scanning calorimetry. Vibrat. Spectroscopy, 50: 68-77.
Petit, T., J. Sperqser, R. Rosengarten and J. Aurich, 2009. Prevalence of potentially bacteria as genital pathogens in dairy cattle. Reprod. Domestic Anim., 44: 88-91.

Rinkinen, M., E. Westermarck, S. Salminen and A.C. Ouwehand, 2003. Absence of host specificity for in vitro adhesion of probiotic lactic acid bacteria to intestinal mucus. Vet. Microbiol., 97: 55-61.

Ruiz, F.O., G. Gerbaldo, P. Asurmendi, L.M. Pascual, W. Giordano and I.L. Barberis, 2009. Antimicrobial activity, inhibition of urogenital pathogens and synergistic interactions between Lactobacillus strains. Curr. Microbiol., 59: 497-501.

Sheldon, I.M., D.E. Noakes, A.N. Rycroft and H. Dobson, 2004. Effect of intrauterine administration of estradiol on postpartum uterine bacterial infection in cattle. Anim. Report. Sci., 81: 13-23.

Tuomola, E.M., A. Ouwehand and S.J. Salminen, 1999. Human ileostomy glycoproteins as a model for small intestinal mucus to investigate adhesion of probiotics. Lett. Applied Microbiol., 28: 159-163.

Voravuthikunchai, S.P., S. Bilasoi and O. Supamala, 2006. Antagonistic activity against pathogenic bacteria by human vaginal lactobacilli. Anaerobe, 12: 221-226.

Wu, Q.X., A.H. Wang, Y.J. Si, L.M. Zhou, H.X. Sheng and Y.P. Jin, 2010. Immortalization of goat endometrial epithelial cells by telomerase transcriptase transfection. Chin. J. Vet. Sci., 30: 228-232.

Zerbe, H., C. Obadnik, W. Leibold and H.J. Schuberth, 2001. Influence of Escherichia coli and Arcanobacterium pyogenes isolated from bovine puerperal uteri on phenotypic and functional properties of neutrophils. Vet. Microbiol., 79: 351-365.

Zhang, Y.C., L.W. Zhang, Y.F. Tuo, C.F. Guo and H.X. Yi et al., 2010. Inhibition of Shigella sonnei adherence to HT-29 cells by lactobacilli from Chinese fermented food and preliminary characterization of S-layer protein involvement. Res. Microbiol., 161: 667-672. 